\title{
Escolas de governo e seu papel estruturante na formação de servidores em tempos de Nova Gestão Pública: relatos de experiências no Nordeste brasileiro
}

Jorge Luiz de Souza Evaristo Universidade Estadual do Ceará (UECE)

Ana Cristina Batista-dos-Santos

Universidade Estadual do Ceará (UECE)

Rafaela Gomes Aguiar

Universidade Estadual do Ceará (UECE)

Juliana Carvalho de Sousa

Doutoranda em Administração pela Universidade Potiguar

Andreza Ferreira Mota Franco

Bacharel em Administração pela Universidade Estadual do Ceará

O texto estuda a relação entre os construtos escolas de governo e Nova Gestão Pública e os articula com o objetivo de compreender o papel das escolas de governo na formação de servidores públicos, no contexto da nova gestão pública brasileira. Metodologicamente, realizou-se uma pesquisa de natureza qualitativa, com uso da entrevista narrativa como técnica de coleta de dados, junto a uma servidora pública responsável pela implementação e gestão de uma escola de Governo (Alfa); uma gestora pública que realizou várias das capacitações promovidas pela EG; e um gestor de órgão público que atua como facilitador e aluno da EG. A técnica de análise dos dados utilizada foi a análise temática de conteúdo, por meio da qual foram identificados os seguintes temas: i) história; ii) papéis; iii) estratégias e ações; iv) dificuldades, todos relacionados à história de Alfa e articulados com a literatura revisada. Conclui-se que, em meio a êxitos e dificuldades, Alfa constitui um caso exemplar do papel das escolas de governo como elementos estruturantes da NGP brasileira, na medida em que essas atuam na formação estratégica dos servidores que são, em última instância, aqueles que tornam possível a implantação dos modelos de gestão pública.

Palavras-chave: escolas de governo, Nova Gestão Pública, pesquisa qualitativa

[Artigo recebido em 30 de junho de 2016. Aprovado em 20 de julho de 2017.] 
Government schools and their structuring role in the formation of public employees in times of New Public Management: reports of experiences in the Brazilian Northeast

The paper investigates the relationship between the constructs government schools and New Public Management and articulates in order to understand the role of government schools in the training of civil servants in the context of Brazil's new public management. Methodologically, was executed a qualitative research, using the narrative interview as data collection technique, next to a public servant responsible for implementing and managing a school of government (Alfa); one public manager that participated in several trainings promoted by the Alfa; and a manager of a public agency who works as facilitator and student of Alfa. The technical of analysis of data based on content thematic analysis, through which the following issues were identified: i) history; ii) roles; iii) strategies and actions; iv) difficulties. All related to the Alfa's history and articulated with the revised literature. We conclude that, amid successes and difficulties, Alfa is a typical example of the role of government schools as structural elements of Brazilian NPM, to the extent that they act in the strategic formation of the servers that are, ultimately, those who make possible the implementation of public management models.

Keywords: government schools, New Public Management, qualitative research

Las escuelas gubernamentales y su papel estructurador en la formación de empleados públicos en tiempos de Nueva Gestión Pública: informes de experiencias en el nordeste de Brasil

El texto estudia la relación entre los constructos escuelas de gobierno y Nueva Gestión Pública y los articula bajo el objetivo de comprender la función de las escuelas de Gobierno en la formación de los servidores públicos, en el contexto de la nueva gestión pública brasileña. Metodológicamente, se realizó una investigación de naturaleza cualitativa, con el uso de la entrevista narrativa como técnica de colecta de datos, el método fue aplicado a una servidora pública responsable de la implementación y gestión de una escuela de gobierno (Alpha); un gestor público que participó de muchos entrenamientos promovidos por Alfa; y un gerente de una agencia pública que trabaja como facilitador y alumno de Alfa. La técnica de análisis de los datos utilizada fue el análisis temático de contenido, por medio del cual fueron identificados los siguientes temas: i) historia; ii) roles; iii) estrategias y acciones; iv) dificultades, todos relacionados con la historia de Alpha y articulados con la literatura revisada. Se concluye que, en medio a los éxitos y dificultades, Alpha constituye un caso ejemplar del rol de las escuelas de gobierno como elementos estructurantes da Nueva Gestión Pública brasileña, en la proporción en que estas actúan en la formación estratégica de los servidores que son, en última instancia, aquellos que tornan posible la implementación de los modelos de la gestión pública.

Palabras clave: escuela de gobierno, Nueva Gestión Pública, investigación cualitativa 


\section{Introdução}

A gestão pública brasileira, na contemporaneidade, tem sido palco da transição de modelos administrativos, donde, com frequência, fala-se de um padrão histórico evolutivo entre os modelos patrimonialista, burocrático e gerencialista, este último frequentemente designado como Nova Gestão Pública (NGP).

A despeito da falta de unanimidade quanto à linearidade das transições entre modelos, haja vista o frequente amálgama entre os mesmos que se observa no cotidiano das organizações públicas brasileiras, esta pesquisa parte do pressuposto de que novos modelos de gestão exigem novos modelos de formação, donde as escolas de governo emergem com um papel estratégico e estruturante, na contemporaneidade.

O objetivo deste trabalho foi, então, compreender o papel de escolas de governo (EG) na formação de servidores públicos, no contexto da NGP brasileira. Empiricamente, realizou-se um estudo de caso único, tendo como sujeitos de pesquisa uma servidora pública que atuou como implementadora e gestora de uma escola de governo num estado do Nordeste brasileiro; uma gestora pública que realizou várias das capacitações promovidas pela EG; e um gestor de órgão público que atua como facilitador e aluno da EG.

Além desta introdução, o trabalho é composto por cinco partes. A segunda aborda a NGP e seus termos alternativos, seguida da terceira parte que discorre sobre as EG. A quarta parte apresenta os procedimentos metodológicos. A quinta parte socializa e discute os resultados. A sexta parte apresenta as considerações finais.

\section{Nova Gestão Pública}

NGP é a nomenclatura brasileira correspondente à corrente britânica New Public Management, proposta a partir da conjunção de sete elementos principais:

Profissionalização da gestão nas organizações públicas; padrões de desempenho e medidas de avaliação com objetivos mensuráveis e claramente definida; ênfase no controle e nos resultados; desagregação das grandes unidades do setor público; introdução da competição no setor público; uso de práticas de gestão do setor privado; ênfase na disciplina e na utilização dos recursos, cortando custos e procurando maior eficiência e economia (Hood, 1991, p. 04 e 05).

A NGP busca a diminuição da ineficiência dos serviços públicos, a partir de ferramentas como a descentralização do poder e da autoridade dos gestores, assim como a divisão e horizontalização das organizações, com o objetivo de assegurar a mudança das regras gerais para os resultados (FONSECA; PEREIRA; GonÇALVES, 2015). 
No Brasil, foi através da Reforma Gerencial de 1995, no governo do então Presidente da República Fernando Henrique Cardoso (1994-2002) e pelo Ministro da Administração Federal e da Reforma do Estado (Mare), Luiz Carlos Bresser Pereira, através do Plano Diretor da Reforma do Aparelho do Estado (PDRAE), que a NGP surgiu. Pautado na eficiência, eficácia e efetividade do aparelho do Estado, com foco em resultados na prestação dos serviços públicos e em mais transparência das atividades (ANDION, 2012), o PDRAE tinha como objetivo assegurar o cumprimento das diretrizes por ele estabelecidas e obedecer às estratégias concebidas em três dimensões: a institucional-legal, compreendendo o papel do Estado e seus aspectos legais; a cultural, em que há a transformação de valores burocráticos para os valores gerenciais; e a gerencial, por meio da qual se pretendia tornar o serviço público mais eficiente e de qualidade para a população (BRASIL, 1995; BRESSER-PEREIRA, 2001).

O modelo brasileiro da NGP foi formulado com inspiração nas ações implantadas na Inglaterra, as quais se caracterizaram por:

Descentralização do aparelho de Estado, que separou as atividades de planejamento e execução do governo e transformou as políticas públicas em monopólio dos ministérios; privatização das estatais; terceirização dos serviços públicos; regulação estatal das atividades públicas conduzidas pelo setor privado; uso de ideias e ferramentas gerenciais advindas do setor privado. (PAULA, 2005, p. 47)

A partir dessas características, surgiram as primeiras ideias de como essas ações poderiam ser executadas no Brasil (BRESSER-PereirA, 2008). Como destaca Paula (2005), foram as ferramentas e práticas de gestão, próprias da administração privada, os grandes vetores que influenciaram o modelo da NGP. No entanto, deve-se levar em conta certas diferenças, como: a) o objetivo de lucro, no caso de organizações privadas, e da realização do interesse público, no caso da administração pública; e b) a origem das receitas, já que as empresas privadas dependem dos pagamentos que os clientes fazem livremente na compra de seus produtos e serviços e a receita do Estado deriva de impostos e contribuições obrigatórias (MANSOLDO, 2009).

O modelo da NGP busca apoiar de forma substancial o aumento da igualdade no acesso aos serviços públicos, bem como a melhoria da eficiência desses serviços. Para isso, utiliza ferramentas como o planejamento estratégico nos projetos a serem desenvolvidos pelo poder público, maior autonomia gerencial, construção de indicadores de desempenho e, acima de tudo, avaliação dos resultados (SILVA, 2013). 
O sistema da NGP teve uma significativa mudança de perspectiva sobre a maneira de alcançar resultados no âmbito público, servindo como celeiro de orientações, métodos e técnicas (SILVA, 2013; FonSECA; PEREIRA; GonÇALVES, 2015). Com a publicação da reforma constitucional em 1998 e com o apoio de políticos e intelectuais, o modelo da NGP não tardou para que fosse aceito pela opinião pública, particularmente pelos administradores públicos (BRESSER-PEREIRA, 2001).

Existem, entretanto, críticas em relação às mudanças propostas pelo modelo da NGP que levaram a sociedade e os servidores a refletir sobre o modelo (EVARISTO; BATISTA-DOS-SANTOS, 2015). Uma das críticas concerne à forma de implementação ou de operacionalização das práticas da NGP, sobretudo a atenção especial à especialização, fragmentação e mercantilização como formas de funcionamento dos serviços da administração pública (SIMIONE, 2014).

Andion (2012) critica a ausência de uma preocupação da NGP com as dimensões política e institucional, deixando o Estado à mercê de forças do ambiente externo sem que o mesmo tenha capacidade de resposta, devendo então submeterse a essas forças. Já autores como Evaristo e Batista-dos-Santos (2015) e Silva (2017) refletem sobre a permanência de aspectos patrimonialistas (nepotismo) e burocráticos (centralização de poder) em algumas esferas do governo, podendo acarretar dificuldades de gerenciamento integral da coisa pública sob uma lógica inteiramente nova, como a dinâmica flexível da NGP.

A despeito das críticas, na NGP, para se alcançar um novo patamar de efetividade, as funções de direção e gerência, em todos os níveis, têm que ser desenvolvidas com base num conjunto de novas ferramentas de gestão e de valores que renovem tecnicamente e eticamente o setor público. É nesse contexto que as EG ganham espaço relevante de atuação para ajudar a produzir as mudanças desejadas, preparando dirigentes e servidores para a nova gestão (PACHECO, 2002), uma vez que cumprem papel ligado às mudanças mundiais e ao modelo de Estado e gestão da coisa pública adotados no devir histórico:

Olhando para trás, vê-se que no Brasil os programas de formação de servidores públicos vieram no bojo dos processos de reforma dos aparatos estatais. As inovações quanto ao tipo de formação e o perfil dos egressos foram e são definidas pelas tendências mundiais, pelo contexto políticoeconômico e pelo modelo do Estado (SouzA, 2002, p. 87). 


\section{Escolas de governo}

As primeiras instituições públicas criadas para fins de qualificação do funcionalismo público sugiram na década de 1940. Como destaque, podemos mencionar: em 1945, o Instituto Rio Branco (IRB); em 1953, a Escola Nacional de Ciências Estatísticas (Ence); e em 1954, a Escola Nacional de Saúde Pública (ENSP). Contudo, nas décadas seguintes, foram criadas outras escolas setoriais com o intuito de capacitar parcelas do serviço público (NAZARETH et al., 2013).

Apenas em meados de 1982 é que se tem as primeiras iniciativas para constituição de uma escola de governo no Brasil. O Departamento Administrativo do Serviço Público (Dasp), após uma solicitação do Ministério das Relações Exteriores, realizou um estudo visando reunir subsídios para a constituição de uma escola de governo no país. Dentre as atribuições do Dasp, pode-se destacar sua incumbência em selecionar e aperfeiçoar o serviço público (ORBAN, 2001).

Dessa forma, a partir dos anos oitenta, foram criadas tradicionais instituições de treinamento voltadas para capacitação da alta direção do estado, como a Fesp, no Rio de Janeiro, a Fundap, no Estado de São Paulo, a Fundação João Pinheiro, em Minas Gerais, dentre outras (ORBAN, 2001).

Acerca de tais escolas de governo, é possível observar diferentes trajetórias em seus processos de constituição. No que diz respeito à Fesp, essa instituição passou a introduzir em seus programas, cursos de pós-graduação na área de administração e gestão de políticas públicas. Acerca da Fundação João Pinheiro, essa instituiu um curso de graduação para formação na área pública estadual. Em São Paulo, a Fundap fundamentou-se na constituição de uma escola de governo aberta à sociedade com inovações metodológicas de ensino (ORBAN, 2001).

Ainda sobre o processo percussor, destaca-se que as EG foram antecedidas tanto por cursos de curta e média duração oferecidos aos servidores públicos, voltados especialmente para a área de recursos humanos, os quais eram, em geral, oferecidos pela Fundação Centro de Formação do Servidor Público (Funcep), criada em 1980; como também, em épocas anteriores, por escolas criadas visando à formação de quadros que se envolvessem no processo de desenvolvimento nacional, e também da América Latina, como a Escola Interamericana de Administração Pública (SouZA, 2002).

No Brasil, tem-se, em 1985, na chamada Nova República (Governo Sarney), uma proposta de reforma administrativa com diretrizes acerca dos recursos humanos, em que o governo enfatizou os objetivos atrelados à valorização do órgão público, avaliando o desempenho e capacitando servidores. Dentro desse contexto, surge a Escola Nacional de Administração Pública (Enap) com o objetivo de formar, 
aperfeiçoar e profissionalizar o servidor. A Enap foi criada em 1986 baseada no Relatório Rouanet, de 1982, que apresentava um estudo sobre os modelos francês e alemão; sendo, então, estruturada tendo como referência a École Nactionale d'Administration, da França (PACHECO, 2000; SOUZA, 2002; ZOUAIN, 2003).

Segundo Souza (2002), a Enap foi criada visando atender às necessidades de reestruturação do Estado face às desarticulações e respostas inexpressivas da máquina burocrática às demandas sociais da época. Para Pacheco (2000; 2002), entretanto, a Enap, em sua origem, ainda estava refém da visão de formação de uma elite burocrática, em virtude da forte influência dos modelos francês e alemão contidos no Relatório Rouanet, mas também como uma retomada do processo de profissionalização burocrática que havia sido iniciado nos anos 1930.

As EG atuais são, então, herdeiras desse processo histórico de transições de modelos de Estado e regimes de governo, e, institucionalmente, fortemente vinculadas à origem e mudanças ocorridas na Enap. Nesse sentido, na contemporaneidade, as EG expressam e promovem, na sua área específica de atuação, a transição entre modelos de administração pública, como argumenta Pacheco (2002):

O papel das escolas de governo tem evoluído no contexto das reformas gerenciais do setor público. Se sua origem foi em geral marcada pelo propósito de formar a futura elite burocrática, tendo como referência os modelos francês e alemão, seu desafio hoje é capacitar os quadros existentes, sobretudo gerenciais e dirigentes, e formar novos profissionais para o setor público que se engajem na superação da cultura burocrática e no exercício dos valores republicanos (PACHECO, 2002, p. 75).

As EG podem ser consideradas como instituições aptas a capacitar os órgãos e agentes públicos, e possuem como objetivo ofertar programas de treinamento e desenvolvimento para os servidores, a fim de obter sua valorização e reconhecimento; mas também agrega-se a elas, sob o ideário da NGP, o importante papel de formação de gestores públicos aptos a tratar das ciências do governo e capacitados a pensar estrategicamente as políticas públicas e a implementá-las visando ao alcance e acompanhamento dos resultados, tendo um enfoque maior nas competências técnicas e políticas (BITTENCOURT; ZOUAIN, 2010; PACHECO, 2002; SOUZA, 2002).

O Decreto no 5.707 (23 de fevereiro de 2006) declarou que serão consideradas EG as instituições destinadas à formação e ao desenvolvimento de servidores públicos, envolvendo a administração pública federal direta, autárquica e fundacional, estabelecendo a Política Nacional de Desenvolvimento de Pessoal; 
e das quais se requer atualização permanente para atuarem como centros de excelência (AIRES, 2014).

A responsabilidade das EG é de estimular a disseminação de conhecimentos dentro da esfera pública, além do desenvolvimento de competências, através de capacitações que envolvem a amplitude de conhecimentos explícitos, tácitos, práticos e teóricos. Contudo, essas escolas enfrentam desafios com relação à capacitação dos servidores e na efetiva contribuição com suas formações (AIRES, 2014).

Busca-se uma nova imagem do serviço público; em vistas disso, as EG buscam avançar em ferramentas de gestão contemporâneas, valorizando e motivando o servidor. Elas são voltadas para o aperfeiçoamento e (re) qualificação, a partir da oferta de cursos, especializações e mestrados profissionais (AIRES, 2014; FADUL et al., 2014).

Algumas EG se configuram como universidades corporativas, voltadas para: (i) aprendizagem dos servidores, (ii) capacitação dos servidores para projetos governamentais estratégicos (FADUL et al., 2014). Bittencourt e Zouain (2010) abordam que as EG podem se subdividir em dois grupos: (i) instituições criadas com a missão de capacitar os servidores, vinculando-se a áreas e carreiras específicas do Estado, (ii) instituição que, não obstante atuarem com capacitação, não se vinculam a nenhuma carreira do Estado, voltando-se para a gama de servidores em todos os níveis e áreas.

É importante ressaltar que as escolas exercem importante influência na vida pessoal dos servidores, ao passo que contribuem para execução de uma administração pública mais eficiente e eficaz em termos de boa gestão. Dessa forma, é imprescindível que as escolas se antecipem no que diz respeito às tendências e melhores práticas, podendo influenciar ativamente a formulação de políticas públicas voltadas para melhoria da gestão (AIRES, 2014).

As EG possuem tendências, como: grande competição entre escolas de governo e fornecedores externos de capacitação; atualização do perfil das instituições universitárias do mercado; semelhança nas ferramentas e metodologias ofertadas pelos fornecedores de capacitação; maior abrangência dos programas que buscam o desenvolvimento gerencial; e escolas atuando de forma mais integrada com as prioridades estratégicas do governo (PACHECO, 2000).

$\mathrm{Na}$ atualidade, tem-se que o processo de formação e capacitação dos profissionais envolve todos os níveis estratégicos, estando vinculado ao processo de inovação e mudanças (BITTENCOURT; ZouAIN, 2010). Para Zouain (2003), o binômio modernizaçãoprofissionalização, vinculado à origem das EG, é insuficiente. Em tempos de NGP, fazse necessário desenvolver a capacidade do governo no processo de aprimoramento de ações dos atores sociais envolvidos com o Estado, desenvolvendo serviços e 
instituindo ações transformadoras, ao invés do governo ser concebido apenas como instrumento de modernização do Estado. Pacheco (2000) aborda que as EG, mediante as dificuldades, devem prospectar o que há de melhor no que diz respeito a conhecimentos e tecnologia, contextualizando o know how dentro da gestão pública.

\section{Procedimentos metodológicos}

A pesquisa foi desenvolvida numa perspectiva integralmente qualitativa, aquela que lida com a compreensão dos fenômenos sociais como seu principal conteúdo de maneira fundamentada na fala dos sujeitos, a partir e sobre as suas vivências, sendo uma abordagem que "trabalha com o universo dos significados, dos motivos, das aspirações, das crenças, dos valores e das atitudes" (MıNAYO, 2013, p. 21).

A técnica de coleta de dados utilizada foi a entrevista narrativa com elementos de história de vida, em que os pesquisadores buscaram levar os entrevistados a elaborarem narrativas livres, porém fundamentadas no mundo vivido, sobre aspectos que consideravam de maior importância no contexto de suas vivências laborais e em suas relações com a EG (BAUER; GASKELL, 2004).

A narração de histórias faz parte da prática de pesquisa social, sendo boa parte do estudo qualitativo exatamente a captura de uma história; não somente a história de uma pessoa ou de um grupo, mas também a história de uma organização ou movimento social (STAKE, 2011). Esse estudo contemplou essas duas perspectivas, na medida em que buscou compreender a história de uma organização (escola de governo), a partir da história pessoal de trabalho de uma servidora pública cujas vivências se desenrolam nesse tipo organizacional, em local estratégico, como implantadora e gestora da escola; bem como pelas histórias de outros servidores que tiveram experiências junto à EG como facilitadores e/ou alunos.

Após assinatura dos termos de consentimento e confidencialidade, os entrevistados foram estimulados a elaborar narrativas a partir dos seguintes tópicos-guias: 1. concepção de escola de governo; 2 . história da escola de governo; 3. principais ações da escola de governo; 4 . as dificuldades enfrentadas pela escola.

A estratégia de pesquisa adotada foi o estudo de caso único realizado numa EG de um estado do Nordeste brasileiro (doravante Alfa). A pesquisa foi realizada através de amostra institucional, que, de acordo com Pires (2008), é o universo de análise que se apresenta ao analista de forma não parcelada e passível de apreensão em sua totalidade. As entrevistas foram realizadas com uma gestora da escola de governo (E1); uma gestora pública que realizou várias das capacitações promovidas pela EG (E2); e um gestor de órgão público que atua como facilitador e aluno da EG (E3). 
Para compreensão dos discursos, foi utilizada a técnica da análise temática de conteúdo, a qual permite a compreensão qualitativa do conteúdo das mensagens através de procedimentos sistemáticos e objetivos (BARDIN, 1977; MıNAYO, 2013). Essa técnica possibilita a nomeação de temas que dão suporte à análise a partir da identificação dos núcleos de sentido (palavras, expressões ou pequenas frases) que expressam o sentido presente nas unidades de contexto (trechos selecionados da narrativa). Os temas ou categorias oriundos desse processo são, portanto, uma síntese da organização e agrupamento dos núcleos de sentido, tomando por base sua proximidade semântica e, no caso da entrevista, o significado subjetivo que o "falante" Ihes atribui.

\section{Resultados e discussões}

Depois de transcritas e categorizadas, as entrevistas foram tomadas como uma narrativa totalizante sobre o objeto. Falas representativas são socializadas no decorrer do texto. Da análise exploratória das entrevistas, foram identificados quatro temas: história; papéis; estratégias e ações; e dificuldades, conforme a Figura 1.

\section{Figura 1 - Temas emergentes}

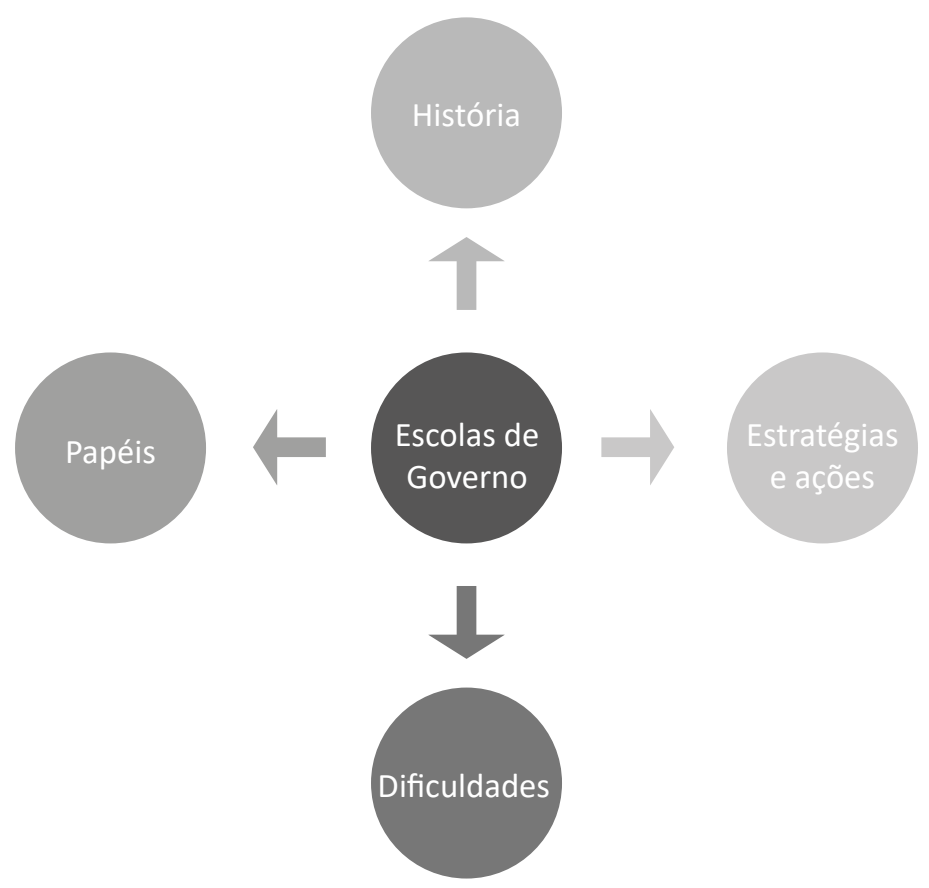




\subsection{História}

As EG estão previstas desde a constituição de 1988, conforme explicita a entrevistada E1: "As escolas de governo, elas estão previstas desde 88, da constituição de $88^{\prime \prime}$. Porém, só foi criado um programa para discutir as propostas do desenvolvimento de carreira, qualidade de vida no trabalho e o programa de desenvolvimento de pessoas, na gestão estadual em questão, entre 2007 e 2008, muito possivelmente como reflexo da publicação do Decreto nํ 5.707, de 2006.

Criamos um programa que era para discutir a questão da proposta do desenvolvimento de carreira. [...] E a gente precisava de alguma coisa que nos desse um retrato [...] e também um instrumento de gestão para ser o acompanhamento. Um desses programas foi o programa que a gente chamou de escola de governo, então ela surgiu como programa em 2007-2008 (E1).

Após o surgimento de Alfa como um programa, com o objetivo de profissionalização do servidor, foi levada a proposta ao governador para, em lugar de ser apenas um programa, passar a ser uma instituição, o que foi aceito. Com isso, Alfa surgiu como algo pequeno, uma experiência, entre março e abril de 2009.

Nós fomos fazendo os programas e entregando para os setores da secretaria de planejamento específicos. Quando chegou na Escola de governo, que era a profissionalização do servidor, e aí nós levamos a proposta para o governador, para uma instituição, ele deixar de ser um programa ou um projeto e passar a ser criado como uma instituição e aí aceitou (E1).

Então ela surgiu como uma coisa pequena, como uma experiência, e numa formação ela ainda hoje é vinculada à secretaria de planejamento; mas é o que a gente chama de órgão descentralizado, ela tem autonomia: o gestor máximo, que a gente chamava de diretor, tem ordenadoria de despesas, ele que determina. Então em maio de 2009, março e abril de 2009 foi quando a escola surgiu e nós desmembramos (E1).

Foi feita uma pesquisa em São Paulo para saber como essas escolas funcionavam, e a partir daí foi elaborada uma proposta para Alfa. Minas Gerais foi o estado referência para a construção da nossa EG, devido a sua escola se preocupar com a carreira do servidor, e sua secretaria de planejamento identificar as necessidades e a escola de Minas construir e executar.

Minas Gerais foi uma referência para gente. Espírito Santo foi uma referência para gente. Quando nós fomos construir a escola do Estado, nós fizemos uma pesquisa em São Paulo e fomos procurando as instituições para saber como elas funcionavam, e em cima disso elaboramos nossa proposta (E1). 
Minas, eles formam carreiras, eles se preocupam com a carreira, é uma instituição dentro da outra, faz parte da carreira do servidor, é tanto que a gente está trazendo um pouquinho para cá, um pouco não, um pinguinho assim da ideia (...) Porque Minas e Rio Grande do Sul, e Espirito Santo, principalmente Minas, eles tinham uma relação forte com a secretaria do planejamento, então a secretaria do planejamento identificava as necessidades, demandava e a escola de Minas construía e executava (E1).

\subsection{Papéis da escola de governo}

O tema papéis da escola de governo emerge pela recorrência de unidades de sentido relacionadas a desenvolvimento, formação de pessoas, profissionalização, capacitação, valorização, bem-estar, cuidado, motivação, democratização, aprendizagem, resultados e gestão do conhecimento.

Institucionalmente, as EG são estruturadas, paulatinamente, para a atividade de formação e desenvolvimento de servidores públicos.

Porque as escolas de governo elas não estão necessariamente ligadas só a gestão não, tem escola de governo, tem escola de governo de saúde pública, mas todas são voltadas para questão da formação do servidor (E1).

Ela [a EG] já organizava o treinamento por completo, já definia o instrutor, tinha uma seleção de instrutores, definia o conteúdo, a forma de inscrição era simples [...] era um ambiente específico só para capacitação (E3).

Na busca do desenvolvimento e da formação de servidores públicos, as escolas relacionam seus objetivos, na contemporaneidade, ao tema das competências e às boas práticas da aprendizagem individual e das interações coletivas. 0 entrevistado E1 relata que "Ela tinha eixos de temas onde se trabalhava e se desenvolvia a questão das competências". Além disso, destaca-se através das falas que a EG possuía como grande objetivo mitigar as desigualdades existentes acerca da distribuição de conhecimentos.

Eu achava que a missão da EG era muito pródiga, era muito importante, era uma forma de diminuir as desigualdades de aprendizagem, de conhecimentos dos servidores do estado, tem pessoas no estado que não teriam outra chance de formação complementar que não fosse através da EG (E3).

O papel é que a EG consiga democratizar ainda mais o acesso a essa formação complementar, que ela traga novos conhecimentos, que ela consiga inserir mais disciplinas de temas mais contemporâneos, que ela consiga atender pessoas do nível estratégico, servidores do nível tático e servidores do nível operacional, todas essas áreas, dos diversos níveis da organização (E3). 
Alfa desenvolveu seus espaços de aprendizagem por meio de estruturas construídas a partir da junção de secretarias do estado e de eixos temáticos, formatados considerando as necessidades dos funcionários e dos gestores.

Nós queríamos fazer uma programação que atendesse à necessidade das pessoas e dos gestores. E acabou que isso nos fortaleceu em termos de eixo [...] vimos que os eixos da Secretaria de Planejamento e Gestão, que era a parte administrativa, a de direito, a de gerência e a de liderança. Aí acabou que a gente construiu eixos em cima disso (E1).

Para ofertar treinamento ou formação no âmbito da gestão governamental e das políticas públicas, de modo autônomo ou buscando parceria com órgãos vinculados ao poder público, a escola formou dois eixos temáticos: o de qualidade de vida no trabalho e o de formação, este último compreendido no sentido de desenvolvimento das competências. Esses eixos seriam direcionados aos servidores e dirigentes do Estado, para proporcionar a profissionalização e desenvolvimento. Tais objetivos convergem com as perspectivas apontadas na literatura quanto à profissionalização do servidor como um dos objetivos das EG (SOUZA, 2002), destacando-se sua importância como um dos elementos estruturantes da NGP, na visão de Hood (1991). Assim, percebe-se que a criação de Alfa estava alinhada com o novo ideário de gestão pública emergente.

Então nós criamos dois programas básicos, que eram os eixos fundamentais da escola: o programa qualidade de vida no trabalho e o programa de formação. Programa qualidade de vida no trabalho voltado para a qualidade de vida no trabalho; e o outro programa no desenvolvimento das suas competências (E1).

A questão do desenvolvimento de competências assumiu lugar de destaque nessa profissionalização, em sentido peculiar à NGP. Embora a profissionalização seja um tema comum também à gestão burocrática, quando se requeria do servidor que fosse alguém "profissionalizado" para o cargo, torna-se relevante perceber que, sob o paradigma da administração pública gerencial, o tema da profissionalização é revisitado agregando-se a ele novos sentidos, donde tem-se que funcionários "altamente profissionalizados [são aqueles com] competências adequadas para atender às demandas da administração pública contemporânea" (SOUZA, 2002, p. 84), competências essas relacionadas, especialmente, ao alinhamento estratégico próprio à gestão por resultados. 
Porque para gente era bem claro aonde a gente queria chegar, a profissionalização do servidor, valorizar o servidor, se trabalha com gestão por resultado, então se trabalha com gestão por resultado. Que resultado nós queremos alcançar? Constrói os objetivos, os objetivos das instituições, metas institucionais, que competência o servidor tem que ter para poder ir buscar esses objetivos, para ter esses resultados, e esse movimento nem todo mundo entende bem claro (E1).

Ela tem um papel importante, ela treina as pessoas num aspecto comportamental, num aspecto técnico, na área de gestão (E3).

Para que isso se consolidasse, o programa de formação contemplava constantemente o desenvolvimento profissional atrelado à valorização dos funcionários para que se chegasse aos benefícios e aos resultados esperados. Nesse sentido, os dois eixos temáticos de Alfa estavam interligados, na medida em que a valorização e reconhecimento no processo de formação eram subsidiados pelos programas de qualidade de vida no trabalho, associando assim formaçãovalorização-reconhecimento (AIRES, 2014).

As pessoas acabavam pegando aquele conhecimento, parte dele ou uma boa parte dele e traziam para o ambiente de trabalho deles e agregavam valores e se sentiam valorizados como servidores, porque estavam sendo capacitados pela instituição e tinha todo esse lado também de motivar as pessoas, de fazer as pessoas se sentirem importantes e agregar novos valores e informações novas, conhecimento novo para o trabalho (E3).

É visto que as EG têm um papel fundamental a ser desempenhado na oferta de programas de treinamento e desenvolvimento de recursos humanos, de modo que seja obtida a valorização do servidor público e seu reconhecimento como cidadão, contribuindo para que este apresente um desempenho de qualidade, mais conhecimentos, motivação e construa uma nova imagem do serviço público.

Cada vez a gente se debruce mais com a missão do servidor, com o compromisso do servidor, com a questão do cuidar $e$ do acolher, a cidadania (E1).

Tanto as pessoas que eu indiquei, como as pessoas que eu trabalhei, no final do curso a gente via que se sentiam bem, as pessoas saiam de lá motivadas, realmente as pessoas saiam com um conhecimento a mais $e$ muitas delas acabam aplicando no dia a dia do trabalho (E3).

Via resultado tanto na forma que ele voltava com aquele conhecimento novo, ele voltava realmente com vontade de aplicar. De modo geral, as pessoas quando voltavam com aquele conhecimento, elas eram motivadas a 
usar e acabava que trazia para o ambiente de trabalho novas técnicas, novas habilidades para os servidores e isso era importante, tanto para o servidor, como para os gestores (E3).

O programa de qualidade de vida no trabalho procurava promover o bemestar dos servidores no seu ambiente de trabalho. Buscavam-se maneiras para se obter uma vida mais satisfatória no ambiente laboral, objetivando-se fortalecer a autoestima, o sentimento de que está sendo cuidado no ambiente de trabalho.

Então o programa qualidade de vida era algo nesse sentido voltado para o bem-estar no trabalho, sem envolver a questão do conhecimento, ele acabava interferindo nas habilidades e nas atitudes, mas no conhecimento ele não entrava de cheio nisso. Mas ele servia como suporte para o outro (E1).

As ações das EG não eram apenas de profissionalização e desenvolvimento dos servidores, mas também de crescimento e evolução junto com eles, pois a ética de resultados, aliada à ética da virtude e da moral, revolucionava todas as atividades no setor público, tanto as gerenciais como as atividades técnicas. Para alcançar esse nível de efetividade, as funções de direção e de gerência em todos os níveis têm que ser desenvolvidas com base em um conjunto de novas ferramentas de gestão e de valores. Esse é o foco para a atuação das EG no contexto atual: ajudar a produzir as mudanças desejadas no setor público, preparando dirigentes e servidores para a nova gestão (PACHECO, 2002); isso também reverberou no discurso dos entrevistados.

Eu também indiquei como gestor de área várias pessoas que trabalhavam para mim ou comigo, para fazer também treinamentos na EG e o pessoal realmente se sentia bem, o resultado era bom, as pessoas voltavam com uma formação a mais, voltavam mais motivadas (E3).

Incluídas no aparato estatal, pôde-se perceber que as EG, como bem exemplifica Alfa, além de serem destinadas à formação de quadros, reciclagem de funcionários e profissionalização, são também direcionadas para construção e disseminação do conhecimento.

A escola de gestão pública foi um espaço, a gente concebeu ela como um espaço de construção de conhecimento e de gestão do conhecimento (E1).

Dos cursos a gente sempre leva alguma coisa nova, sempre aprendi alguma coisa [...] e aí também depende da pessoa ter vontade e ter disposição, força e determinação para aplicar aquele conhecimento novo, de repente você até repassar aquele treinamento ou pedaço dele para as pessoas do setor que você trabalha, servindo como multiplicador, então era assim que eu tentava trabalhar e assim que acontecia comigo pelo menos (E3). 
Buscam não apenas capacitar servidores públicos que compõem o Estado, mas instituir um ambiente de aprendizagem contínuo, no qual os servidores possam criar, adquirir e compartilhar conhecimentos. Um novo cenário se colocava para as EG: não se tratava mais de apenas formar futuros quadros, mas de deixar espaços abertos para novos desafios.

É papel das EG estimular a disseminação de conhecimentos dentro da esfera pública (AIRES, 2014). É nesse contexto que os entrevistados ressaltam a importância da gestão do conhecimento, que se transformou em um valioso recurso estratégico para criação de espaços nas escolas, para a vida e ambiente de trabalho dos servidores.

As EG promovem a gestão do conhecimento, registrando e validando suas experiências, incentivando as parcerias, as comunidades de aprendizagem e o compartilhamento de experiências institucionais, de modo a fomentar a gestão das competências e habilidades dos servidores, resultando para os servidores o seu desempenho, a sua motivação e o seu comprometimento com a organização da qual fazem parte, a fim de que essa cumpra fielmente sua missão institucional.

\subsection{Estratégias e ações}

Alguns tipos de estratégias e ações utilizados para o cumprimento dos papéis de Alfa foram identificados no discurso dos entrevistados: estratégias gerenciais, estratégias relacionais e estratégias operacionais.

A NGP utiliza ferramentas como o planejamento estratégico nos projetos a serem desenvolvidos pelo poder público, maior autonomia gerencial, a construção de indicadores de desempenho e, acima de tudo, a avaliação dos resultados alcançados (SILVA, 2013). Dentro desse contexto, foi identificada, no discurso, uma estratégia política inicial, a união da Secretaria de Administração com a Secretaria de Planejamento, que deu origem à Coordenadoria de Desenvolvimento de Pessoas.

Alfa é colocada por E1 e E2 como uma estratégia de gestão com função de controle e gerenciamento, instrumentos que a gestão pública necessitava para o acompanhamento do desenvolvimento do servidor. As funções de controle e gerência da escola, por sua vez, confirmam o que Hood (1991) denomina como elementos da NGP, próprios à lógica da gestão privada: ênfase no controle e nos resultados.

E a gente precisava de alguma coisa [...] um instrumento de gestão para ser o acompanhamento. Um desses programas foi o programa que a gente chamou de escola de governo (E1).

Mas assim eu também vejo que quando sai algum sistema novo, a escola de gestão tenta fazer um curso daquele tipo [...] quando eles vão fazer um sistema novo que tem que ser usado em todos os órgãos do estado, eles fazem isso (E2). 
A estratégia relacional identificada foi a criação de redes de parceria; essas se deram em dois âmbitos: o interno e o externo.

No âmbito interno, aproveitou-se dos próprios talentos e conhecimentos existentes dentro da estrutura do Estado. A E1 que, à época de formulação da lei que constituiu Alfa, participou do processo de concepção da mesma, agiu estrategicamente no sentido de favorecer a participação de servidores como professores de Alfa. Já E2 destaca a experiência que os facilitadores tinham em relação aos conceitos ensinados. Esses recebiam gratificações e tinham a saída autorizada no seu horário de trabalho rotineiro para ministrar os cursos e oficinas promovidos pela escola. Esse processo de transformação do servidor em professor (e também em aluno) que repassa seus conhecimentos para outros servidores cumpre o papel das EG de disseminação de conhecimentos/capacitações envolvendo amplitude de conhecimentos (AIRES, 2014).

Então assim, a lei, nós criamos dentro da lei de criação da escola, que eu dizia que era o pulo do gato nosso, que era o que? Tem lá permitindo que o aluno servidor saia do seu horário de trabalho e vá assistir aula, e permitindo que o professor servidor saísse do seu horário de trabalho e fosse dar aula e ganhasse, além do salário dele, ele ganhava gratificação, e esse foi um dos fatores que contribuíram para o desenvolvimento da instituição como um todo, porque as pessoas se sentiam como pertinente, pertencia a ele e se sentia valorizado, o servidor que é convidado ainda ganha, pouquinho mas ganhava, ele estava ganhando duas veze (E1).

o curso era muito bom, o facilitador era experiente na área [...] você encontra bons profissionais lá dando o curso (E2).

No âmbito externo, foram mapeadas as escolas que possuíam programas de profissionalização, principalmente em estágios mais desenvolvidos, e formou-se uma rede para o desenvolvimento de programas conjuntos, com o intuito de que uma escola desse suporte às demais. A criação dessas redes é, segundo Pacheco (2002), um objetivo da NGP, que busca parcerias efetivas e motivação de dirigentes e da alta gestão, gerentes e funcionários para obtenção de resultados mais efetivos.

Trouxemos a ideia de fazer uma rede aqui, porque eu acredito que o meu limite pode ser superado com a sua possibilidade, e o seu limite pode ser superado com a minha possibilidade. Identifiquei quais as escolas de governo ou unidades dentro de uma instituição que funciona como profissionalização do servidor público, fiz o mapeamento, convidei essas escolas e formamos a rede estadual de escola de governo. Em cima disso, nós fizemos vários programas (E1). 
A alta gestão entender que todas as pessoas precisam ser capacitadas, cada uma dentro do seu nicho, fazer entender que todas as pessoas da instituição das suas mais diversas áreas têm que ter capacitação, claro que dirigida para o que ele faz (E3).

Os entrevistados E1 e E2 destacam, ainda, um último tipo importante de estratégia utilizada em Alfa: as estratégias de operacionalização. Foram elas: cursos, oficinas, seminários; mas também ações voltadas à reflexão sobre o conhecimento construído individualmente ou coletivamente com um foco tanto no trabalho técnico, mas também agregando um olhar estratégico para as políticas públicas, em consonância com o que trata a literatura.

Geralmente quando a gente envia algum funcionário para fazer o curso é porque [a área dele] está ligada ao curso. Eu nunca indico uma pessoa para fazer o curso que não é daquela área. Mas, por exemplo, tem gente aqui da equipe que já foi fazer curso na escola de gestão e aplica [...] o pessoal da área de desenvolvimento de sistemas (E2).

O que era que eu pensava que era um dos papéis das escolas de governo: é a questão da profissionalização do servidor público, mas a profissionalização do servidor não necessariamente implica em formação, em curso, oficina, mas também na produção de conhecimento em políticas públicas, então, tanto na questão da reflexão como na construção desse conhecimento. Então, por exemplo, para a gente uma das estratégias curso, oficinas, seminário, o que for, é estratégia para se construir conhecimento, construir individualmente, construir socialmente nos grupos. Eu sempre concebi que escola de governo é um espaço de construção e de reflexão, ela é um espaço de construção de conhecimento por meio da reflexão do fazer (E1).

É interessante observar que todo esse processo de construção do conhecimento individual e coletivo que foi inspirado e incentivado em Alfa coaduna com a ideia do uso de ferramentas de gestão contemporânea que as EG devem promover através da oferta de cursos, especializações, mestrados profissionais aos servidores (AIRES, 2014; FADUL et al., 2014).

\subsection{Dificuldades}

A partir das narrativas sobre as vivências em Alfa, os entrevistados também socializaram as dificuldades envolvidas no processo de gestão da EG em estudo. As principais dificuldades elencadas foram autonomia de recurso, acompanhamento e monitoramento, liberação do funcionário e o fazer sistêmico e intersetorial. 
Foram apontadas tanto dificuldades pontuais quanto dificuldades de maior abrangência. Uma dificuldade pontual, destacada pelos entrevistados E1 e E3, foi a de liberação do funcionário no horário de expediente mesmo com as estratégias de garantia dessa possibilidade previstas no marco legal:

E uma das dificuldades era a questão do recurso e a liberação do servidor para capacitação (E1).

As dificuldades às vezes está na alta gestão, dependendo da área que você trabalha, tem gestores que acham que tirar a pessoa do trabalho por 20 horas, por uma semana, por duas semanas para fazer um treinamento, vai fazer com que alguma coisa deixe de ser feita, vai trazer algum prejuízo para instituição, não consegue perceber o ganho disso no médio longo prazo. Então tem pessoas que dificultam a saída de um servidor, quanto mais ele é importante num local, quanto melhor ele trabalha, quanto mais ele se dedica aquele trabalho, às vezes, mais dificuldade ele tem para sair para fazer uma capacitação e é a pessoa que mais merece ser capacitado, até por reconhecimento, até uma forma de demonstrar que você reconhece, que ele é importante (E3).

Quanto às dificuldades de maior abrangência, E1 afirma que "tem-se dificuldade em trabalhar intersetorialmente", discurso que pode auxiliar na compreensão dos relatos de E2, em que esses abordam como dificuldades a aplicação do conhecimento apreendido nos cursos da escola de governo, pois as chefias e órgãos superiores não incentivam ou inviabilizam essa aplicação por razões diversas.

Eu vejo, é uma das maiores dificuldades é a forma como você concebe o mundo e a sociedade, entendeu? Essa coisa do sistêmico que hoje cada vez ela se faz mais forte, né? Um influenciando o outro, a gente não consegue, as pessoas têm mais dificuldade de ver isso (E1).

O governo faz as coisas e a gente nem sabe exatamente o que está acontecendo [...] por exemplo, teve um curso que foi até de uma ferramenta de gerenciamento de conteúdo [...] até eu mandei o web designer para esse curso porque era da parte dele e depois quando ele estava voltando desse curso ele comentou comigo que na escola de gestão foi comentado que o governo já está querendo mudar essa plataforma (E2).

A falta de um pensar e fazer sistêmicos torna-se um obstáculo no trabalho nos órgãos públicos desse estado, e, por consequência, um desafio para as ações de Alfa. Isso se desvela como um distanciamento ou dificuldade no uso de ideias e ferramentas advindas do setor privado, característica marcante da NGP (PAULA, 2005), já que o pensamento sistêmico é o fulcro da gestão privada pelo menos 
desde meados do século 20. Essa falta se evidencia na dificuldade dos servidores significarem o seu fazer em relação com o fazer dos outros e do todo. Há dificuldades envolvidas com o processo de compreensão e assimilação da importância do processo de capacitação e desenvolvimento individual.

A meu ver uma das maiores dificuldades é que as pessoas, os servidores em comum, ele não dá o significado ao fazer dele, porque ele não está vendo a ligação que ele tem a ver com isso, entendeu? Quando ele percebe, aí ele entra com o compromisso [...] dá significado ao seu fazer (E1).

Essa falta de visão sistêmica pode ter relação com outra dificuldade apontada pelos entrevistados E1 e E2: a resistência gerencial.

O gestor resistia porque ele queria o servidor dele naquela hora, naquele momento [...] eu mesma fiz ações indo visitar gestores, explicando o que era uma escola de governo, explicando o que era esse programa para poder ter uma aceitação maior (E1).

E a outra é a questão dos papéis dos gestores, nessa coisa da capacitação, do desenvolvimento de pessoas, se bem que isso está melhorando muito (E1).

Tanto tinha gente que voltava do curso e encontrava espaço aberto para aplicar o conhecimento, como também tinham pessoas que faziam o treinamento e quando voltavam com um conhecimento novo, as pessoas um conhecimento que o gestor desconhecia e por desconhecer acabava ficando um pouco ascético para aplicar e as pessoas também tinham essa dificuldade de aplicar e tinha certa frustração (E3).

Percebe-se que há uma resistência da gestão para acatar a implementação de novos projetos, havendo resistências quanto ao posicionamento dos gestores dentro do processo de capacitação. Esse determinante apontado pela entrevistada também vai na contramão do patamar de efetividade defendido pelos autores, pelo qual se defende que a gerência em todos os níveis tem que ser desenvolvida com base em novas ferramentas de gestão (PACHECO, 2002).

Uma das dificuldades mais atuais e significativas, na visão da entrevistada E1, é a que se relaciona ao controle dos resultados, isto é, à dificuldade de acompanhamento e monitoramento do resultado das ações de Alfa no trabalho individual, com repercussões sistêmicas na gestão pública de todo o estado.

Mas também muita dificuldade que eu sinto é a questão do acompanhamento e monitoramento, na minha avaliação. A gente não tem isso nas duas instâncias, estadual e municipal, e se você perguntar, as outras escolas elas também têm dificuldade (E1). 
Uma das dificuldades que a gente teve, que ainda hoje sinto essa dificuldade, é o acompanhamento e o monitoramento das ações, porque você faz o diagnóstico, planeja a intervenção, executa a intervenção, e há as dificuldades de monitorar e acompanhar os resultados disso (E1).

Percebe-se que a questão do monitoramento dentro da escola é um processo que necessita de melhorias, principalmente no que diz respeito ao acompanhamento dos resultados a partir dos projetos instituídos. Há, assim, de forma clara, uma dificuldade em relação a um dos princípios basilares da NGP, no que se associa aos padrões de desempenho e medidas de avaliação. Ao não ter esses instrumentos de acompanhamento dos resultados das ações estratégicas adotadas, Alfa se distancia da possibilidade de mensurar os objetivos previamente estabelecidos (HOOD, 1991; SILVA, 2013).

Finalmente, uma última dificuldade elencada foi a falta de autonomia em relação aos recursos para investimento na formação dos servidores, dificuldade que, de certa forma, vem na contramão das tendências da NGP relacionadas à autonomia gerencial (HOOD, 1991; SILVA, 2013). Por outro lado, converge para as práticas de corte de custos a fim de obter eficiência e economia, tão próprios à NGP (HOOD, 1991). Porém, ressalte-se que o corte de recursos em áreas como a de formação pode se traduzir como um erro estratégico.

Um dos nossos desafios para nova gestão é como fazer para poder você ter mais autonomia na questão dos recursos (E1).

Então assim, a outra dificuldade que eu senti enquanto gestora da escola era na questão dos recursos, porque você sabe que a primeira coisa a ser cortada é a capacitação. E aí assim, nesse caminhar, que foram 6 anos de escola de governo, a gente teve que mostrar com ações a importância da profissionalização para o servidor (E1).

E alguns cursos que até eu já solicitei à escola de governo, mas ainda não foi atendido, mas aí não é nem por conta da escola de governo, é por conta do... de próprio recurso do governo que não repassa (E2).

Essa dificuldade de recursos também atrapalha dela [a EG] captar novos professores, com melhor formação, que tenha perfil de instrutor com mais conhecimento, com mais didática [...] isso compromete muito a formação, a capacitação (E3).

A partir das falas socializadas acima, pode-se perceber que a problemática dos recursos é sentida por todos entrevistados como um dos fatores limitantes da capacidade formativa da EG. Entretanto, a questão da falta de recursos nos órgãos públicos também compromete a possibilidade de aplicação dos conhecimentos adquiridos pelos servidores da EG na rotina de trabalho, conforme relata E2: 
Em algumas coisas sim, em outras acaba que não muda [a rotina] porque a gente não tem condições de aplicar dentro do trabalho da gente. Muitas vezes a gente aprende uma coisa lá fora e quando chega aqui dentro a realidade é outra. Para a gente aplicar aquele conhecimento, a gente precisa ter mais recurso, a gente precisa ter um equipamento diferenciado (E2).

\section{Considerações finais}

A pesquisa foi realizada com vistas à compreensão do papel das EG na formação de servidores públicos, no contexto da nova gestão pública brasileira. Após realização da pesquisa de campo, quatro temas responderam ao objetivo proposto.

Pelo primeiro tema, conclui-se que a história de Alfa é típica dos tempos de NGP, e se explica tanto por sua constituição formal num tempo em que o ideário da NGP já era plenamente conhecido no Brasil, quanto pela busca de experiências exitosas de outras EG, em estados brasileiros pioneiros e representativos na implantação de uma administração gerencialista, como é o caso de Minas Gerais, exemplificando assim um caso de mimetismo organizacional exitoso na gestão pública.

A análise e discussão do segundo e terceiro temas - papéis; estratégias e ações - mostra a presença das premissas da NGP tanto na concepção quanto na implementação de Alfa. Diversas técnicas gerencialistas, herdeiras da gestão privada, emergiram no discurso, tais como: diagnóstico organizacional, planejamento estratégico, formação baseada em competências, gestão do conhecimento, controle de resultados, bem como o uso de ferramentas estratégicas "além muros", como a criação de redes interorganizacionais, com ênfase na parceria e transferência de know how.

As dificuldades, que emergiram como quarto tema, apontam as principais contradições que envolvem o objeto de estudo, pois, a despeito do pensamento gerencialista ter embasado a constituição da escola e suas principais estratégias, ao mesmo tempo, percebe-se que é a ausência de algumas premissas do pensamento gerencialista que tem dificultado o alcance do êxito desejado. Dentre as principais dificuldades estão: i) a falta do pensamento sistêmico; ii) a resistência da gerência; iii) a falta de mecanismos gerenciais de acompanhamento e monitoramento das ações de Alfa, visando a um efetivo controle dos resultados. 
Conclui-se que, em meio a êxitos e dificuldades, Alfa constitui um caso exemplar do papel das EG como elementos estruturantes da NGP brasileira, na medida em que atuam na formação estratégica dos servidores que são, em última instância, aqueles que tornam possível a implantação dos modelos de gestão pública. Os relatos das experiências obtidas pelos entrevistados fornecem dados importantes para orientação de novas escolas, bem como aprimoramento das existentes.

\section{Referências bibliográficas}

AIRES, R. F. DE F. et al. Escolas de governo: o panorama brasileiro. Revista de Administração Pública, v. 48, n. 4, p. 1007-1027, 2014.

ANDION, C. Por uma nova interpretação das mudanças de paradigma na administração pública. Cadernos da Escola Brasileira de Administração Pública e de Empresas, Rio de Janeiro, v. 10, n. 1, p.1-19, mar. 2012. Disponível em: <http://www.scielo.br/pdf/ cebape/v10n1/03.pdf>. Acesso em: 14 ago. 2015.

BARDIN, Laurence. Análise de Conteúdo. São Paulo: Edições 70, 1977.

BAUER, M. W.; GASKelL, G. Pesquisa qualitativa com texto, imagem e som: um manual prático. Petrópolis: Vozes, 2004.

BITTENCOURT, M. A.; ZOUAIN, D. M. Escolas de governo e a profissionalização do Servidor Público: estudo dos casos da Escola de Serviço Público do Estado do Amazonas - ESPEA e da Fundação Escola de Serviço Público Municipal de Manaus FESPM. Revista ADM.MADE, v. 14, n. 2, p. 75-94, 2010.

BRASIL, Plano Diretor da Reforma do Aparelho do Estado, de novembro de 1995. Disponível em: <http://www.bresserpereira.org.br/Documents/MARE/ PlanoDiretor/planodiretor.pdf>Acesso em: 08 de agosto de 2015.

BRESSER-PEREIRA; L. C. Do Estado patrimonial ao gerencial - In: PINHEIRO, WILHEIM e SACHS (orgs.), Brasil: um século de transformações. SP: Cia. das Letras, 2001.p. 222-259.

BRESSER-Pereira; L. C. O modelo estrutural de gerência pública. Revista de Administração Pública. Rio de Janeiro, v. 42, n. 2, p. 391-410, mar./abr. 2008.

EVARISto, J. L. S.; BATISTA-DOS-SANTOS, A. C. Mudanças na administração pública brasileira: do Estado patrimonialista à Nova Gestão Pública. 67ạ Reunião da Sociedade Brasileira para o Progresso da Pesquisa (SBPC). 2015. Disponível em: http://www.sbpcnet.org.br/livro/67ra/resumos/ resumos/3142_1410a8682fb819abb7fd210999d28e251.pdf. Acesso em: 25 dez. 2015.

FADUL, É. et al. Administração pública no Brasil: reflexões sobre o campo de saber a partir da Divisão Acadêmica da Associação Nacional de Pós-Graduação e Pesquisa em Administração (2009-2013). Revista de Administração Pública, v. 48, n. 5, p. 1329-1354, 2014. 
FonsecA; J. A.; PereiRA; L. Z.; GonçALVES; C. A. Retórica na construção de realidades na segurança pública: abordagens dos sistemas de Minas Gerais e São Paulo. Revista Administração Pública - Rio de Janeiro, v. 49, n. 2, p. 395-422, mar./abr. 2015.

Hood, C. A public management for all seasons? Public Administration, v. 69, p. 3- 9, Spring, 1991.

MANSOldo, M. Evolução histórica dos modelos administrativos da administração pública: o princípio da eficiência no atendimento público. 2009. Monografia apresentada à Unifenas.

MınAYo, M.C.S. Pesquisa social: teoria, método e criatividade. Petrópolis, RJ: Vozes, 2013.

NAZARETH, P. A. et al. O papel da escola de contas e gestão do Tribunal de Contas do Estado do Rio de Janeiro na promoção de culturas inclusivas na gestão municipal. In: SEMINÁRIO INTERNACIONAL DE INCLUSÃO EM EDUCAÇÃO: UNIVERSIDADE E PARTICIPAÇÃO, 3, 2013, Rio de Janeiro, Anais... Rio de Janeiro, RJ, 2013.

ORBAN, J. S. Escola de governo e escolas de serviço público: limites e problemas (estudo de caso da fesp-rj e fundap-sp). Dissertação (Mestrado em Administração Pública) - Fundação Getúlio Vargas, Rio de Janeiro, 2001.

PACHECO, R. S. Escolas de Governo como centros de excelência em gestão pública: a perspectiva da Enap - Brasil. In: Revista do Serviço Público/Fundação Escola Nacional de Administração Pública. Brasília: Enap. v. 53, n. 1, jan/mar. 2002.

PACHECO, R. S. Escolas de governo: tendências e desafios - Enap-Brasil em perspectiva comparada. Revista do Serviço Público, v. 51, n. 2, p. 35-53, 2000.

PAULA, A. P. P. D. Por uma nova gestão pública: limites e potencialidades da experiência contemporânea. Rio de Janeiro: Editora FGV. 2005.

PAULA, A. P. P. D. Escolas de governo: tendências e desafios - Enap - Brasil em perspectiva comparada. In: Revista do Serviço Público/Fundação Escola Nacional de Administração Pública. Enap. Brasília. v. 51, n. 2, p. 35-53. , 2000.

PIRES, A. P. Amostragem e pesquisa qualitativa: ensaio teórico e metodológico. In: PoupART, J. et al. A pesquisa qualitativa: enfoques epistemológicos e metodológicos. Rio de Janeiro: Vozes, 2008.

SHEPHERD, G.; VALENCIA, S. Modernizando a administração pública na América Latina: problemas comuns sem soluções fáceis. In: Revista do Serviço Público, Brasília, ano 47, v.120, n. 03, p. 103-128, set./dez., 1996.

SILVA, A. C. Evolução da administração pública no Brasile tendências de novos modelos organizacionais. Pós-graduando em Gestão Pública com ênfase em Licitações e Contratos - ICE - Cuiabá - 2013. Disponível em: <http://www.ice.edu.br/TNX/ storage/webdisco/2013/12/13/outros/27b4d512efbac7d37520bc37aa78cac1. pdf>. Acesso em: 19 de junho de 2015.

SILVA, R. G. Fenômeno dos conflitos nas relações sociais de trabalho em organizações públicas, no contexto da nova gestão pública: um estudo na perspectiva da psicodinâmica do trabalho. 2017. 128 f. Dissertação (Mestrado) - Mestrado Acadêmico em Administração, Centro de Estudos Sociais Aplicados, Universidade Estadual do Ceará, Fortaleza, 2017. 
Simıone, A. A. A modernização da gestão e a governança no setor público em Moçambique. Revista de Administração Pública, v. 48, p. 551-570, 2014.

SouzA, E. C. L. DE. A capacitação administrativa e a formação de gestores governamentais. Revista de Administração Pública, RAP-FGV, v. 6, n. Xxiv, p. 73-88, 2002.

StAKe, R. E. Pesquisa qualitativa: estudando como as coisas funcionam. Porto Alegre: Penso, 2011.

ZouaIN, D. M. Escolas de governo e escolas de serviço público: limites e problemas. Estudo de caso da Fesp/RJ e Fundap/SP. VIII Congreso Internacional del CLAD sobre la Reforma del Estado y a de la Administracion Pública, p. 28-31, 2003.

\section{Jorge Luiz de Souza Evaristo}

Instituição à qual é vinculado: Universidade Estadual do Ceará (UECE). Doutorando em Administração pela Universidade Estadual do Ceará. Mestre em Administração pela Universidade Estadual do Ceará. Bacharel em Administração pela Universidade do Ceará. Graduando em Direito pela pela Universidade do Ceará. Contato: jorgeluiz0807@gmail.com

\section{Ana Cristina Batista-dos-Santos}

Instituição à qual é vinculada: Universidade Estadual do Ceará (UECE). Docente e pesquisadora na Universidade Estadual do Ceará. Líder do Grupo de Pesquisa Integra Saberes sobre Trabalho, Organizações e Gestão da UECE. Doutora em Administração pela Universidade Federal do Rio Grande do Norte. Mestre em Administração pela Universidade Estadual do Ceará. Contato: ana.batista@uece.br

\section{Rafaela Gomes Aguiar}

Instituição à qual é vinculada: Universidade Estadual do Ceará (UECE). Vice-Líder do Grupo de Pesquisa Integra Saberes sobre Trabalho, Organizações e Gestão da UECE. Mestre em Administração pela Universidade Estadual do Ceará. Especialista em Gerenciamento de Projetos pela Universidade de Fortaleza. Bacharel em Administração pelo Centro Universitário Estácio de Sá do Ceará. Contato: rafagomes.aguiar@gmail.com

\section{Juliana Carvalho de Sousa}

Doutoranda em Administração pela Universidade Potiguar. Mestre em Administração pela Universidade Estadual do Ceará. Especialista em Gestão Estratégica de Pessoas e Liderança Organizacional pela Faculdade Vale do Jaguaribe. Bacharel em Administração pela Universidade Federal Rural do Semi-Árido. Contato: juli.cs1009@gmail.com

\section{Andreza Ferreira Mota Franco}

Bacharel em Administração pela Universidade Estadual do Ceará. Contato: andrezaferreira90@gmail.com 